\title{
Relationships Between External Factors and University Students' Attitudes towards Academic Research
}

\author{
Leah Li Echiverri, Jiying Yang, Feng Tang \\ College of Liberal Arts, Wenzhou-Kean University, China.
}

\begin{abstract}
Research is an important part of an academic career, yet it is not always frequently practiced by most students. This descriptive-correlational research aimed to find out the external factors that influence students' attitudes toward research. The researchers sampled 201 undergraduates at Wenzhou-Kean University and analyzed their responses to the questionnaire in order to determine the relationship between possible factors and their attitudes. The results revealed that the external factor of the training environment has a moderate positive influence on research attitude, while support from the university has a strong positive influence on research attitude. Specifically, factors of faculty support, curriculum design, on-campus academic activities, library service, and financial support all moderately influence students' attitudes towards research in a positive way. The most salient influential factor of all is faculty support. The results suggested that to improve students' attitudes towards research, sufficient support is vital, especially academic and financial support. Therefore, to externally encourage students to conduct academic research, faculty and university could give more consideration to support provision.
\end{abstract}

Keywords: Academic research; research attitude; research training environment; university support. 


\section{Introduction}

Research conduct is one significant part of society's academic advancement, which also plays an essential role in the personal academic career. Specifically, for undergraduates, it is a necessary skill to learn, for it prepares them to produce academic outcomes, which will influence their admission to graduate schools. Moreover, research benefits students by assisting them in attaining knowledge on a much deeper scale and inspiring them to learn confidently, independently, and proactively with better communication skills, retention, and persistence. (Stanford et al., 2017). Therefore, academic research should not be overlooked in undergraduate education.

However, studies have discovered that among undergraduates, only a small percentage holds a positive attitude toward academic research. In general, there is no research culture cultivated in universities. (Van der Linden et al., 2015). For various reasons, students lack information, exposure, or merely interests in academic research, resulting in unawareness of the value of academic research, as well as little participation in research.

To have a better understanding of why the above phenomenon exists, this study aimed to explore and describe external factors that influence students' attitudes toward academic research. The study mainly focused on the research training environment and support from the university, using analysis of survey responses from students at Wenzhou-Kean University (WKU). Connections between these two factors and students' attitudes may provide educators and instructors with possible directions to inspire students to view academic research more positively.

\subsection{Literature Review}

\subsubsection{Attitudes Towards Academic Research}

Students' attitudes towards research are variable. The results from previous researches revealed that the majority of students held positive attitudes towards research study. Only a minority of them were interested in conducting their own research projects at the same time (Kozlova \& Atamanova, 2013). Thus, shaping attitudes became a priority in high educational settings. Various elements could be evaluated and discussed in this topic. Accordingly, there were two aspects to infer students' research attitudes: research knowledge and personal research experience. Research knowledge is used as a criterion to examine students' research output. "Acquiring deep and sound knowledge" was one of the major motives for students towards academic research (Kozlova \& Atamanova, 2013). Undergraduates' performances in academic research were affected by their early research experiences (Stanford et al., 2017). 


\subsubsection{Research Training Environment}

The research training environment is referred to as an overall atmosphere that relates to academic research. The past researches had suggested that the audiences of research skills include all university graduates, regardless of their future career path (Murtonen et al., 2008). In the context of the WKU campus, the training system consists of a research curriculum and faculty support. A case study in Russia revealed that a research-related curriculum aims at developing students' motivations and shaping their positive attitudes towards academic research (Kozlova \& Atamanova, 2012). What to be offered in curriculums have a great influence on students' research attitude. Faculty support here is generally referred to as the instruction and help coming from faculty. In the past surveys, "Being respected by tutors and approved by other people" and "Following tutor's requirements and setting a good example for peers" are listed on the motives for a research study (Kozlova \& Atamanova, 2013).

\subsubsection{Support from the University}

University-level support is noticeably powerful in encouraging research conduct. A study reported that on-campus academic activities could increase students' confidence and appreciation of research, leading to postgraduate study (John \& Creighton, 2011). Furthermore, Xi et al. (2019) discovered that more reputable universities with stronger academic backgrounds have relatively better reference services of libraries. This correlation suggests library service's impact on research attitudes. According to Evans (2010), financial support from the university is another essential factor for a positive outcome of undergraduate research. More student participation ensues from increased university financial support (Stanford et al., 2017). It should also be considered that a sufficient amount of funds directly impacts the feasibility of the research in terms of necessary equipment and other costs.

\subsection{Conceptual Framework}

\subsubsection{Operational definition of the terms}

Attitudes towards Academic Research: The perceptions of academic research and willingness to participate in academic research. Specific indicators include students' research knowledge and research experience.

Research Training Environment: The academic research atmosphere in university considering the cultivation of students' research ability. This is indicated by the design of the research curriculum and faculty support.

Support from the University: The provision made by the university, from which faculty and students benefit. Indicators are on-campus academic activities, library services, and financial support provided by the university. 


\subsubsection{Conceptual Framework Graph}

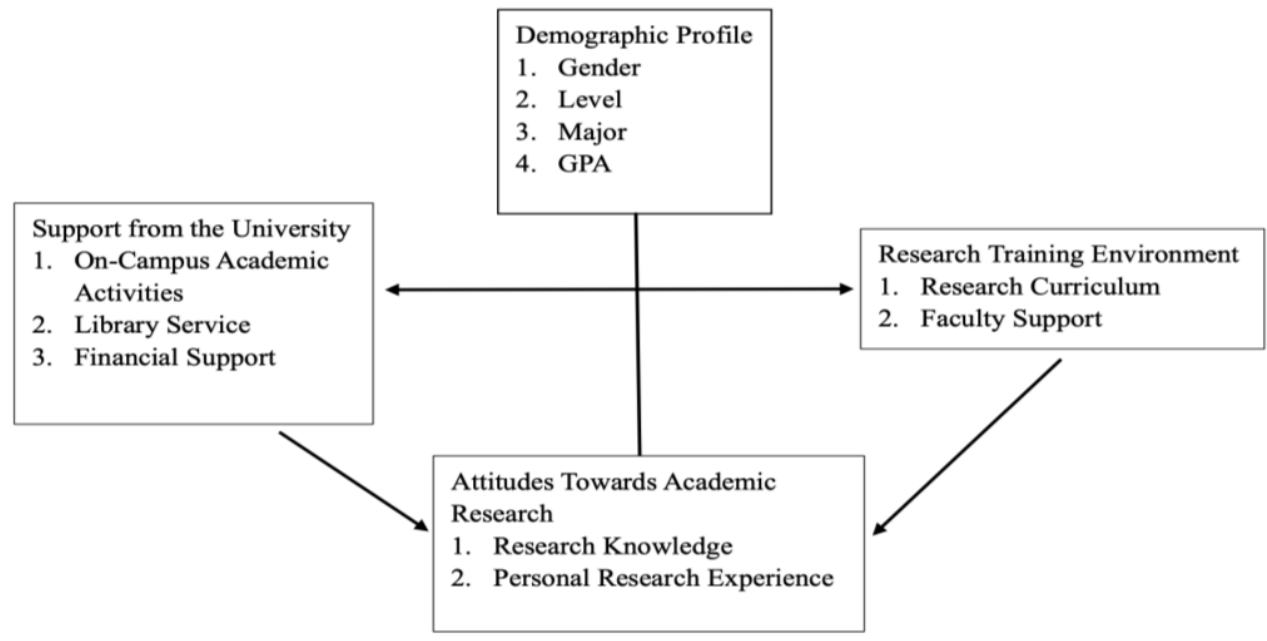

Figure 1. Conceptual Framework

\section{Methodology}

Descriptive-correlational and cross-sectional designs were used in the study, serving to determine the correlation between external factors and students' attitudes towards academic research. The research was conducted at Wenzhou-Kean University which is an institution that is collaborated between China and the United States. The current undergraduate programs in WKU adopt the American education system.

Two hundred and one responses were collected as research samples, which were nearly $10 \%$ of the total student population at WKU. All the responses were proved to be complete and valid. The data came from all four colleges across four grades in WKU, during the Fall Semester of 2019, which freshly reflected the current academic research situation at Wenzhou-Kean University.

Peer critiquing was used to establish the validity and reliability of research instruments. This study used a quantitative approach by means of an online survey administered via WeChat in an open and closed-ended questionnaire. A four-point Likert scale was used to measure the respondents' attitudes towards academic research, support from the university and research training environment. In the scale, number 4 represented strongly agree (SA), while number 1 represented strongly disagree (SD). 


\section{Results and Discussion}

\subsection{Research Training Environment and Students' Research Attitudes Relationship}

Faculty support in the research training environment was observed to have a moderate positive impact on students' research attitude $(\boldsymbol{R}=.553)$. What was noteworthy about the statistics was, all descriptive indicators' coefficients were lower than the overall coefficient, among which the highest was $(\boldsymbol{R}=.526$, $)$ the lowest was $(\boldsymbol{R}=.451)$. This suggested that when all independent indicators were combined and taken into consideration together, there was an extra positive impact on students' interests in research. Table 1 presents the statistics of faculty support's impact.

Table 1. Relationship between faculty support and students' research attitudes

\section{Indicators}

Academic research attitudes

$\mathbf{R}$

.526

.451

Overall Faculty Support

.553

\section{* Correlation is significant at the 0.05 level}

Regarding research curriculum design in the research training environment, both conditions of existing research courses $(\boldsymbol{R}=.393)$ and extra training opportunities $(\boldsymbol{R}=.354)$ had a weak positive impact on research interests. The correlation coefficient $(\boldsymbol{R}=.476)$ of helpful feedback from faculty ranked the highest among all the indicators related to research curriculum design, followed by the correlation coefficient $(\boldsymbol{R}=.468)$ of students' satisfaction in current courses. Same as faculty support, overall considerations of research curriculum design showed more positive results than each independent indicator. In general, the relationship between research curriculum design and students' academic research interests was moderate positive. Table 2 presents the statistics of the relationship between research curriculum design and students' research attitudes. 
Table 2. Relationship between research curriculum design and students' research attitudes

\begin{tabular}{ccc} 
& $\mathbf{R}$ \\
\hline - $\quad$ Existing research courses in a four-year plan & .393 \\
- $\quad \begin{array}{l}\text { Extra training opportunities } \\
\text { (lecture/workshop/competition) }\end{array}$ & .354 \\
- $\quad$ Students satisfaction on current courses & .468 \\
Overall Research Curriculum Design & .476 \\
\hline
\end{tabular}

* Correlation is significant at the 0.05 level

\subsection{Support from the University and Student's Research Attitudes Relationship}

The results reported that WKU students generally recognized the helpfulness of the support from the University, which overall had a strong positive impact on their attitudes toward research. Among all the indicators which were considered moderate positive, financial support ranked the highest $(\boldsymbol{R}=.466)$, followed by library service $(\boldsymbol{R}=.452)$, library resources of related materials $(\boldsymbol{R}=.444)$, and on-campus academic activities $(\boldsymbol{R}=.271)$. Similar to previous statistics but with a more noticeable leap, once combined all independent indicators, the relationship between research attitudes and support from the University becomes strongly positive. Table 3 presents the statistics of support from the University.

Table 3. Relationship between support from the university and Student's Research Attitudes

\section{Indicators}

Academic research attitudes

$\mathbf{R}$

- On-campus academic activities

.271

- Library service

- Library's offer on related materials

- Financial support

\section{Overall Support from the University}

.720

* Correlation is significant at the 0.05 level

Results revealed that there is a significant positive relationship between WKU students' attitudes towards academic research and external factors. Both major factors, support from the university and research training environment, have a moderate positive impact on 
students' research attitudes. This result was in accordance with several past studies about academic research from John and Creighton (2011), Xi et al. (2019), Stanford et al. (2017), Evans (2010), Murtonen et al. (2008), Kozlova and Atamanova (2012, 2013), and David (2003). As for the highlights of this research, it combined independent factors studied in previous researches and did an overall evaluation of undergraduates' academic research situation, specifically at Wenzhou-Kean University, a typical Sino-foreign university.

\subsection{Support students expect to receive from the university}

Findings of the open-ended question reported other support students expect to receive. Among 201 responses, 109 answers were valid, of which 73 (67\%) respondents gave suggestions concerning academic aspects. The 36 (33\%) respondents provided suggestions concerning non-academic aspects. In general, students anticipate more academic improvement from the University, including opportunities to be exposed to research (21\%), professional instructions (38\%), and others $(8 \%)$ considering academic issues. Another noteworthy indicator was financial support for academic research, proposed by 32 (29\%) respondents. Table 4 presents the detailed responses provided by respondents.

Table 4. Support students expect to receive from the University.

\begin{tabular}{|c|c|c|c|c|}
\hline $\begin{array}{c}\text { (Non-) } \\
\text { Academic }\end{array}$ & Category & Subcategory & Number & Note \\
\hline \multirow{9}{*}{$\begin{array}{l}\text { Academic } \\
\text { Total: } 73\end{array}$} & \multirow{4}{*}{$\begin{array}{l}\text { Opportunity } \\
\text { (exposure to } \\
\text { research) }\end{array}$} & Library & 3 & retrieve and learn from other research \\
\hline & & $\begin{array}{l}\text { Research } \\
\text { recruitment }\end{array}$ & 4 & join research \\
\hline & & conferences & 15 & publish research and learn from others \\
\hline & & $\begin{array}{l}\text { Publication } \\
\text { platform }\end{array}$ & 1 & publish research \\
\hline & \multirow{3}{*}{$\begin{array}{l}\text { Instructions } \\
\text { (preparation } \\
\text { for research) }\end{array}$} & Course & 8 & l \\
\hline & & Workshops & 18 & $\begin{array}{c}\text { including game, case sharing, and other } \\
\text { activities }\end{array}$ \\
\hline & & Professor & 15 & l \\
\hline & \multirow{2}{*}{ Others } & Credit replacement & 1 & / \\
\hline & & Not specified & 8 & l \\
\hline & & From school & 31 & / \\
\hline $\begin{array}{c}\text { Non- } \\
\text { academic }\end{array}$ & Finance & Social scholarship & 1 & l \\
\hline \multirow{2}{*}{ Total: 36} & Time & Enough time & 2 & l \\
\hline & Reward & Certificate & 2 & / \\
\hline
\end{tabular}


Students' expectations of university support mostly expressed were concerns related to academic aid and financial support. Based on ranking, the highest demands were 1) financial aid from the school, 2) research-related workshops, 3) conference opportunities, 4) professors' instructions, 5) modified curriculum.

\subsection{Practical Implications}

For faculty support to help students better prepare themselves for conducting research, it is suggested that more research-oriented activities such as $\mathrm{SpF}$ and $\mathrm{SpS}$ programs be appropriately granted, thereby anticipating an increase in students' participation in experiential research learning. Likewise, stepping up of after class mentoring and instructions is recommended. These conditions will likely cultivate students' positive attitudes towards academic research since students enjoy being immersed in a positive training environment.

For curriculum designers, to be able to expand students' research knowledge, hone students' research skills, and develop students' research potentials, researchers propose to enhance the four-year plan to incorporate more discipline-based research courses. Thus, students are more likely to equip themselves with fundamental skills tailored fit to their field of specialization. In addition, the inclusion of research related training activities and opportunities such as institutional based or interuniversity conferences and workshops is being recommended. Students' exposure to these activities will enhance students' current course satisfaction.

For school administrators, it is expected to provide students with more financial support on research, including awarding scholarships and reimbursing related fees.

Researchers believe these implications are applicable to similar educational environments and encourage the associated part to take measurements in providing relative support to their students.

\subsection{Conclusions}

A significantly positive and moderate correlation of external factors and students' attitude towards academic research was established for Chinese students learning in an EMI context. Students' research attitudes are shaped by both the support from the university and the research training environment. There are some additional support students expect to receive from the university. Top priorities are financial support from the school, research-related workshops, conference opportunities, professors' instructions, and modified curriculum. 


\section{References}

Evans, D. R. (2010). The Challenge of Undergraduate Research. Peer Review, 12(2), 31.

John, J., \& Creighton, J. (2011). Researcher development: the impact of undergraduate research opportunity programmes on students in the UK. Studies in Higher Education, 36(7), 781-797.

Kozlova, N. V., \& Atamanova, I. V. (2012). The Effect of the Training Programme on Students Motivation for Research Activity. Problems of Psychology In The 21st Century, 3, 42-52.

Kozlova, N. V., \& Atamanova, I. V. (2013). The Development of Undergraduates Motivation for Research Work. Procedia - Social and Behavioral Sciences, 93, 498-502. doi: 10.1016/j.sbspro.2013.09.227

Kumar, R. (2019). Research methodology: A step-by-step guide for beginners. Sage Publications Limited.

Murtonen, M., Olkinuora, E., Tynjälä, P., \& Lehtinen, E. (2008). "Do I need research skills in working life?": University students' motivation and difficulties in quantitative methods courses. Higher Education, 56(5), 599-612. doi: 10.1007/s10734-008-9113-9

Stanford, J. S., Rocheleau, S. E., Smith, K. P., \& Mohan, J. (2017). Early undergraduate research experiences lead to similar learning gains for STEM and Non-STEM undergraduates. Studies in Higher Education, 42(1), 115-129.

Van der Linden, W., Bakx, A., Ros, A., Beijaard, D., \& Van Den Bergh, L. (2015). The development of student teachers' research knowledge, beliefs, and attitude. Journal of Education for Teaching, 41(1), 4-18.

Xi, Q., Wu, W., Ji, J., Zhang, Z., \& Ni, F. (2019). Comparing the Level of Commitment to In-Depth Reference and Research Support Services in Two Sets of Chinese Universities. Science \& Technology Libraries, 1-20. 